pudding. On the 7 th, at 9 A.M., he had had a goor night, although he hitd taken no chloral, sleeping on and off from 10 P.M. to 8 L.M. He had a cup of tea, with bread in it, for brealkfast. The edges of the tongue and gums were sore and tender. The rash had quite gone. The right arm was less firmly contracted, and he could move the fingers a little. At 9 P.M. he had had a good day. On the 8th he slept fairly well without chloral. The right arm and hand were rather more rigid than on the day preceding. He was ordered bread and milk. He said that washing the arm cansed slight spasm. He could now put out the tongue a little. On the 9th he had had a good night. The bowels acted, and he had a satisfactory day. On the 10th he had slept rell. He could put out the tongue further, although the jaws could not be opened much more than before. He sat up for three hours and had minced beef and vegetable marrow. On the 11th he had had a good night. The tongue was cleaning. He sat up for three hours. On the 12th he had again had a good night. He was out on the verandah in the sunlight for an hour. On the 13th he weighed 10 st. $3 \mathrm{lb}$, and was sent home, as his wife was anxions for his return. During the next two months he was seen at intervals. The tonic contraction of the right arm, though gradually decreasing, persisted until Oct. $20 \mathrm{th}$. On Nov. 15th he came to report himself. He still complained of general muscular weakness. His weight was $12 \mathrm{st} .3 \mathrm{lb}$.

Remarks.-In this case the origin of the infection is pretty apparent. The antitoxin was administered in the following way. It was powdered finely in a mortar and dissolved in 90 minims of boiled distilled water. It was then injected, by means of a sterilised syringe, deeply into the muscles of the back. After the first injection great pain followed each succeeding dose, and the tissues round looked red, swollen, and inflamed. The patient had evidently a dread of them, as they made him feel terribly upset for some hours. At first the antitoxin seemed to do good by lessening the frequency and severity of the spasms, but the later injections appeared to cause great and alarming weakness. Although he was carefully fed during the whole time with milk, raw eggs, prepared meat juice, and brandy, he lost nearly $2 \frac{1}{2}$ st in weight. The tonic contraction of the right arm continued nearly six weeks after the acute attack had subsided. The swelling on the ulna also completely disappeared about the same time. It is, of course, doubtful in this case whether either the antitoxin or the chloral hydrate had anything to do with the favourable result, but it is, perhaps, best to publish notes of each patient treated with antitoxin, and it is certainly interesting to compare this case with the one published by Dr. 'Tirard. ${ }^{1}$ Tandell says, in summing up Cowling's report on Tetanus:" "Recoveries from traumatic tetanus have been usually in cases in which the disease occurs subsequent to nine days after the injury. When the symptoms last fourteen days recovery is the rule, apparently independent of treatment. The true test of a remedy is its influence on the history of the disease. Does it cure cases in which the disease has set in previous to the ninth day? Does it fail in cases whose duration exceeds fourteen days? No agent tried by these tests has yet established its claim as a true remedy for tetanus." In how many cases has tetanus antitoxin been tried when the symptoms have come on at an early date after the injury, and what have been the results?

Thirsk, Yorks,

\section{A CASE OF CYSTIC TUMOUR OF THE LARYNX.}

Br G. HCNTER MACKENZIE, M.D., C.M. EdIN., SURGEOY TO FHE EYK, EAR, AND THROAT INITRMARY, HDIXBURGH.

A MAN aged sixty-seven years applied at the Edinburgh Eye, Ear, and Throat Infirmary on June 4th, 1895, on account of " difficulty in breathing," which had existed in a marked degree for above a year and had become more pronounced during the last three months. For several nights preceding admission he had had scarcely any sleep on account of a sensation of impending suffocation which sometimes caused him to spring suddenly out of bed for relief. He had always enjoyed good health until the onset of his present trouble.

1 THE LanceT, Nov. 2nd, 1895

2 American Practitioner, September, 1870.
His voice was husky, and there was well-marked laryngeal stridor, but no pain. On laryngoscopic examination the cause of his respiratory embarrassment was at once detected. A pear-shaped body with a smooth surface lay upon and obscured the left vocal cord and part of the left rentricular band. It was attached by a short pedicle at or near the anterior commissure of the cords and extended as far as the left arytionoid cartilage. 1t moved slightly with ordinary

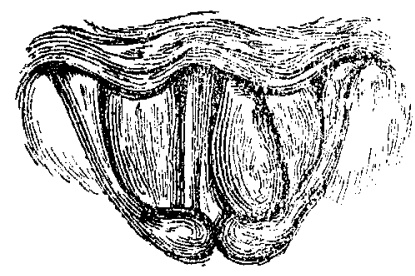

respiration, but during deep inspiration it was drawn below the level of the glottis. The obstructing body was at once removed by the aid of rectangular laryngeal forceps, and a portion of the pedicle which remained was removed by a second similar operation. Immediate and complete relief followed the operation. No recurrence had occurred four months afterwards. After removal of the tumour a somewhat rare condition of the larynx was observed. The left vocal cord, which at first seemed to underlie the tumour, was now found to have completely disappeared, apparently from long-continued pressure and erosion by the growth. A portion of the left ventricular band had been similarly affected.

Remarks.-It is worthy of special notice that two cases of cystic tumour of the larynx in old persons-the one being in almost all respects a duplicate of the other-should have occurred at this clinique within a comparatively limited period. The previous case (already reported ${ }^{1}$ ) was that of a woman eighty years of age who was operated on in a similar manner to the case now under notice. and who is still alive without any recurrence of the tumour. The rarity of these cases is shown by the fact that of 100 cases of growth in the larynx published by the late Sir. Morell Mackenzie only two were cystic. The important inference one is justified in drawing from these and other similar cases is that cystic tumours of the larynx after removal show little or no tendency to recur.

Edinburgh.

\section{A CASE OF PELVIC HæMATOCELE.}

\section{By ERNEST WILLIAM BLISS, M.R.C.S. ENG.,} L.R.C.P. LOND.,

ASSISTANT MEDICAL SUPERINTENDENT, ST, MARYLEBONE INTIRMARY.

THE following case is one of sufficient interest to warrant its being recorded.

A married woman was admitted to the St. Marylebone Infirmary on Aug. 21st, 1895. The history given by herself was that she had always been healthy up to the date of her marriage three years previously. She had one child eleven months after marriage ; the labour was normal. Two months after the birth of this child she states that she suffered from "inflammation of the bowels" and was laid up for one month. No history of any other illness was elicited. Her present illness developed one month before admission, when she was attacked by pains about the rectum and all round the lower part of the abdomen. These pains increased in severity for a fortnight, when she passed from the vagina two small clots each about the size of the " end of her fore. finger." She had not been unwell for two months before her illness and thought that she was pregnant. On Aug. 9th-that is, twelve days before admission to the infirmary-she became unwell and lost a good deal of blood for about a week, when the flow ceased altogether. On the 17th, four days previously to her admission, she was suddenly attacked by very severe pain in the lower part of her abdomen and felt very faint. She saw her medical attendant, who immediately sent her home to bed, and from that time till her admission to the infirmary she remained in great pain. When first seen there she had an anxious, pinched expression; the temperature was $101.6^{\circ} \mathrm{F}$; the 
face was pale and rather sallow, but the body was well nourished. On examining the abdomen there was found occupying the hypogastric region a globular swelling, which was hard to the touch and consistent with the feel of a gravid uterus. The swelling extended about two inches and 2 half above the symphysis pubis. The breasts were flaccid, and no milk could be squeezed from them. Examination per raginam disclosed no discolouration of the vaginal mucous membrane. The os was fairly hard and round and was not dilated. Bimanually a large globular mass could be felt accupying the pelvis in the middle line, but extending more to the right than to the left side. The patient's condition remained much the same for the next few days. The temperature ranged from $99^{\circ}$ to $103^{\circ}$, generally being raised most at night. She complained of very severe pelvic and abdominal pain, which was much exaggerated when the bowels were moved. During this time the pelvic swelling increased slightly in size, especially laterally. On Sept. 3rd chloroform was anministered and a thorough examination made. The uterus was made out to be suite distinct from the swelling, and to be pushed high up behind the pubes; it was reached with difficulty. In Douglas's pouch there was a large swelling bulging the posterior vaginal wall forwards and extending laterally on both sides of the pelvis, but more so on the left side. This was the reverse of her condition on admission. Bimanually fluctuation could be distinctiy made out in the swelling. From this time (Sept. 3rd) to Sept. 13th the patient's condition remained about the same. The temperature was raised, and pain continued. The pelvic swelling, if anything, increased laterally, but not much ehange was observed. On the morning of Sept. 13th she began to pass blood per vaginam, and during that day she massed a number of clots of blood. From the moment she commenced to lose blood she experienced relief from the pain, and during the whole period of her convalescence she kad no return of it. The bowels were moved without pain, and the temperature became normal. For the next two says she continued to pass blood (fluid and clotted), and on an exámination being made per vaginam it was found that the whole of the mass occupying Douglas's pouch had disappeared. There was no pain on examination. The os could be made out easily and was in its normal position. The uterus was freely movable. Some roughness could be felt high up in the posterior vaginal wall, and on passing a speculum this was seen to correspond with what appeared to be a rough granulating surface round the opening from which the blood had been discharged. 'The discharge of blood ceased, and from this time till she left on Oct. 5th she made an uninterrupted recovery.

Remarks. - This case I take to be one of pelvic hæmatocele, and, considering the history of cessation of menstruation for two months, the passage of what she describes as two clots about a fortnight before admission, and the sudden attack of severe pain and faintness four days before admission, $\mathrm{I}$ think it was most probably caused by the rupture of an extra-uterine gestation. Unfortunately, the clots first passed were not reserred, and I was therefore unable to examine them. The method of cure in this case is, I think, not its least interesting feature. No operative procedure was considered to be adrisable or was attempted. I am indebted to $\mathrm{Mr}$. J. R. Lunn, medical superintendent of the infirmary, for permission to publish this case.

Ladbroke-grove-road, $\mathrm{W}$.

\section{\& CASE OF DIPHTHERIA TREATED BY ANTI-DIPHTHERITIC SERUM.}

\section{Br W. A. HOLIIES, M.D. EdIN., D.P.H. CAMrs.}

THE patient, a girl aged five years and eleven months, of a plethoric temperament and subject to hypertrophied tonsils, was attacked on April 5 th by diphtheria. The parents were told by a neighbour that she thought it was a severe case of mumps. The objective signs were considerable enlargement of the parotid glands in front of and behind each ear, as also of the submaxillary and sublingual glands to such an extent as to hicle the real line of the neck. Uatwardly it had all the appearances of a severe case of mumps, the glandular swellings being very hard. The remperature was normal; the pulse was full, good, and quite regular. On the soft palate, on the right side, there was a small abscess which broke during the afternoon; the tongue was dry, with a white fur on it; the tonsils wore hypertrophied and the uvula was much swollen; the tonsils and pharynx were both covered with an ash-grey looking membrane which did not extend into the pharynx, although it was covered with a glairy-looking mucus, as was also the uvula. In the evening there was neither aggravation nor amelioration of the symptoms, thus indicating that ordinary treatment for diphtheria was holding the disease in check. The following morning at 5.20 A.M. the diphtheria had assumed an alarming state of affairs. The patient was pulseless, the face being livicl, the lips cyanosed, and the eyes fixed and covered with a glairy mucus. The fingers up to the hands were cyanosed, the tongue was dry and rolled up like a ball in the mouth, the entire soft palate, uvula, pharynx, larynx, and nose as far as the external meatûs were covered by the diphtheritic membrane, and the breathing was stertorous. She was lying powerless, with an occasional movement of the head to ease the stertorous respiration. The arms when lifted fell like pieces of lead. The skin was very hot, but the temperature was not taken. There was no perspiration. With the patient in such an utterly hopeless state I decided to use anti-diphtheritic serum. I injected 20 c.c. of the serum-i.e., 10 c.c. subcutaneously between the spinal column and scapula on each side. Two minutes after the injection the respiration was easier; in five minutes the stertor was less marked, and on the whole she was much relieved from the embarrassed respiration, giving great relief to both parents and nurse. Two and a half hours after the injection the lividity of the face and the cyanosis of the fingers and lips had been replaced by the hue of health. The temperature was normal; the pulse was good, full, and otherwise normal. Her countenance rvas now expressive of anxiety, the sclerotics and cornea were free from scum, and the eyes were movable. She was able to lift the hands and arms; the tongue could be protruded half an inch beyond the lips, and was not so dry as previously. With such a clecided improvement 10 c.c. of anti-diphtheritic serum were again injected subcutaneously, slightly higher on the back than the previous one on the right. Two hours after this second injection of serum a marvellous change took place in the state of the patient. She now sat up of her own accord and began to speak, but with a difficult phonation, yet every word spoken could be heard and understood; her speech was nasal. Two hours and fifteen minutes after the second injection she recognised and admired a hyacinth which had been brought in and placed in a corner of the room; she also recognised everyone and everything about her. The nurse, who had been in the Monsall Fever Hospital and had had considerable experience in nursing diphtheria patients, said she could scarcely realise the change which had been brought about, remarking that she had never seen so bad a case of diphtheria. The urine voided during the day was scanty, but contained neither albumin nor sugar, and was of specific gravity 1018. To remedy the scantily voided urine, steam from hot water in a basin, and afterwards from a bronchitis kettle, was resorted to. Two drachms of perfumed carbolic acid were added to two pints of water, and the steam produced was allowed to diffuse about the patient for two hours, thrice in the twenty-four hours, at a distance of three feet from the patient. The throat was mopped occasionally with weak Condy's fluid, and flower of sulphur was occasionally blown into the throat until the diphtheritic membrane disappeared. This was done for two days subsequently. On the first day after the injection the quantity of urine voided was much more than on the previous day, and less difficulty was experienced, this being probably due to the carbolic acid reducing the irritation of the renal epithelium. The carbolic acid in no way reduced the good effects of the anti-diphtheritic serum circulating in the blood stream. The temperature was normal and the pulse as satisfactory as before. By the evening the diphtheritic membrane had disappeared from the roof of the mouth, the urula, and the nose, the pharynx and larynx alone being covered with it. There was a copious, irritating, watery discharge from both nostrils, excoriating the skin below the nasal meatûs down to the margin of the upper lip. On the second day after the injection the general state of the patient was good. There was still the irritating watery discharge from the nostrils, but the parotid and sublingual glands on each side were much softer, the pharynx and larynx were free from the diphtheritic rnembrane, and urine was voided 